MIDPI

MOL2NET, International Conference Series on Multidisciplinary Sciences http://sciforum.net/conference/mol2net-03

sciforum

\title{
Comments on Tetracarbonyl(pyrrolylimine) Complexes of Rhenium
}

Antoine Simonneau ${ }^{\mathrm{a},}$, Franck Le Bideau ${ }^{\mathrm{b},{ }^{*}}$, Jean-Hugues Mirebeau ${ }^{\mathrm{c}}$, Jérôme Marrot ${ }^{\mathrm{d}}$, Gérard Jaouen ${ }^{\mathrm{c}}$

${ }^{a}$ Laboratoire de Chimie de Coordination du CNRS, UPR 8241, 31077 Toulouse cedex 4, France.

${ }^{b}$ BioCIS, Université Paris-Sud, CNRS, Université Paris-Saclay, 92290, Châtenay-Malabry, France; ${ }^{c} I P C M, U M R$ 8232, Université Paris 06, CNRS, F-75005, Paris, France

${ }^{d}$ Institut Lavoisier de Versailles, Université de Versailles-Saint-Quentin-en-Yvelines, 78035 Versailles, France

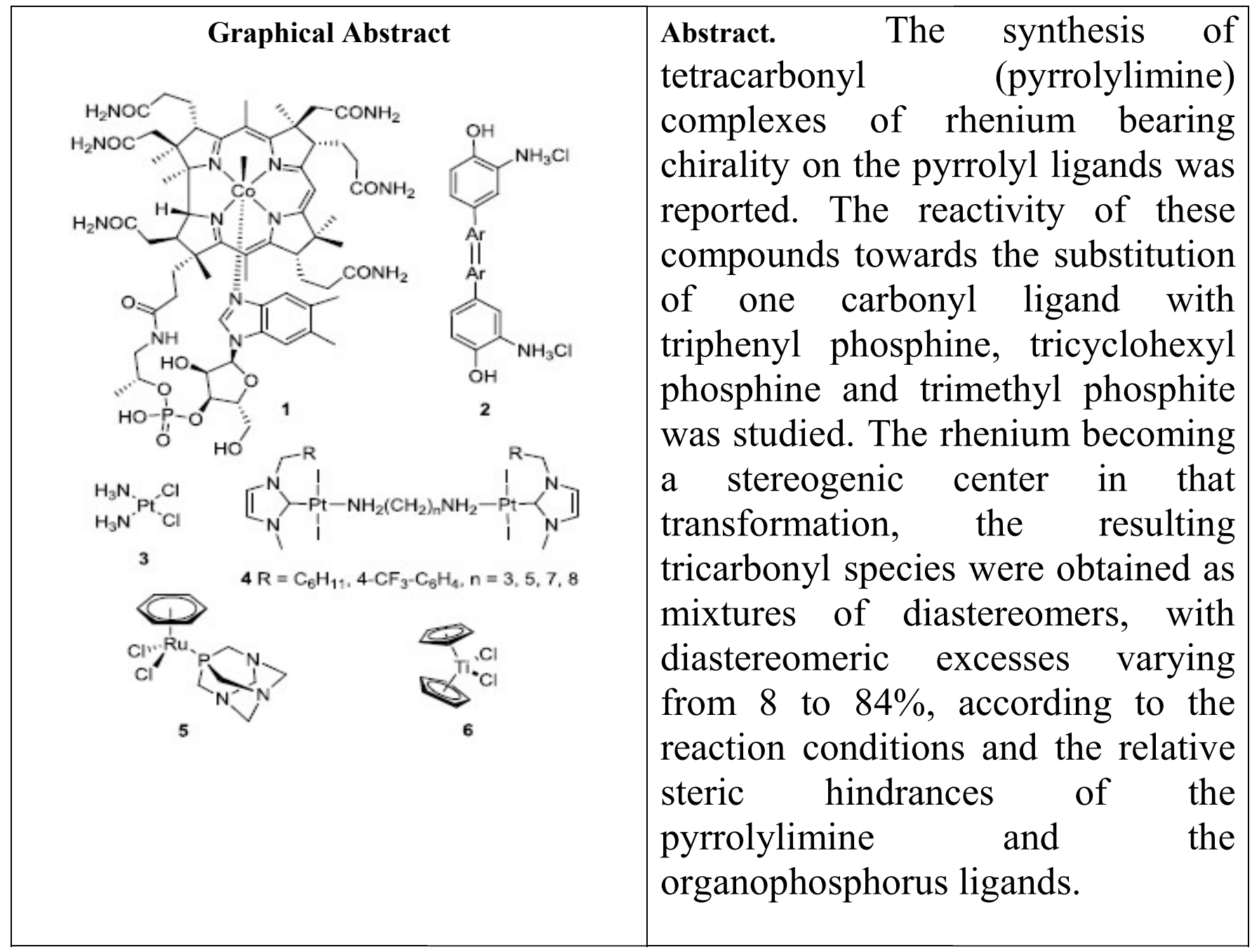

\section{Reference:}

Curr Top Med Chem. 2017 Jul 19. https://www.ncbi.nlm.nih.gov/pubmed/28730956 